\title{
Anesthesiologist's satisfaction using between cisatracurium and rocuronium for the intubation in the anesthesia induced by remifentanil and propofol
}

\author{
Hyunjung Lee ${ }^{1}$, Sinho Jeong ${ }^{1}$, Cheolhun Choi $^{2}$, Hyejin Jeong ${ }^{1}$, Seongheon Lee ${ }^{1}$, and Seongwook Jeong ${ }^{1}$ \\ Department of Anesthesiology and Pain Medicine, ${ }^{1}$ Chonnam National University Medical School, Hwasun, ${ }^{2}$ Gwangju KS Hospital, \\ Gwangju, Korea
}

Background: Although cisatracurium has many advantages in anesthetic practices, the best choice of a nondepolarizing neuromuscular blocking agent that can replace succinylcholine is rocuronium. However, it is reported that remifentanil with propofol might provide reliable intubating condition, even without a neuromuscular blocking agent; therefore, it might improve the intubating condition with cisatracurium. This study examined intubating conditions after administering rocuronium or cisatracurium in a rapid sequence induction with remifentanil-propofol.

Methods: Fifty two ASA physical status 1 or 2 adult patients scheduled for an elective surgery were enrolled in a randomized double-blinded trial. Anesthesia was induced in all patients with propofol $2.0 \mathrm{mg} / \mathrm{kg}$ and remifentanil $0.5 \mu \mathrm{g} / \mathrm{kg}$, administered over 60 seconds. Rocuronium $0.9 \mathrm{mg} / \mathrm{kg}\left(3 \times \mathrm{ED}_{95}, \mathrm{R}\right.$ group, $\left.\mathrm{n}=23\right)$ or cisatracurium $0.15 \mathrm{mg} /$ $\mathrm{kg}\left(3 \times \mathrm{ED}_{95}\right.$, C group, $\left.\mathrm{n}=29\right)$ was administered after the induction sequence. Laryngoscopy was attempted when the anesthesiologist thought it was 90 seconds after drug administration and appropriate time for intubation. The examiner, another anesthesiologist, recorded the exact time to intubation and suppression of maximal T1 on TOF. The intubating condition was assessed by the first anesthesiologist, as excellent, good, poor or not possible.

Results: The best time to laryngoscopy was predicted by measuring TOF and was found to be significantly longer in the $\mathrm{C}$ group (197 $\pm 53 \mathrm{~s}$ ) than in the R group (102 $\pm 49 \mathrm{~s})$ (P value < 0.05$)$. However, time to larygoscopy, intubating condition during the laryngoscopy, and hemodynamic changes after intubation was similar in both groups.

Conclusions: Despite fundamentally slower onset time, cisatracurium can provide quite good intubating conditions, which were comparable to those achieved with equipotent doses of rocuronium, which is more expensive in anesthesia inducted with remifentanil and propofol. (Korean J Anesthesiol 2013; 64: 34-39)

Key Words: Cisatracurium, Intubation, Rocuronium, Satisfaction, TIVA.

Received: May 23, 2012. Revised: July 11, 2012. Accepted: July 30, 2012.

Corresponding author: Seongwook Jeong, M.D., Ph.D., Department of Anesthesiology and Pain Medicine, Chonnam University Hwasun Hospital, 322, Seoyangro, Hwasun-eup, Hwasun-gun 519-763, Korea. Tel: 82-61-379-8750, Fax: 82-62-232-6294, E-mail: anesman@jnu.ac.kr

(c) This is an open-access article distributed under the terms of the Creative Commons Attribution Non-Commercial License (http:// creativecommons.org/licenses/by-nc/3.0/), which permits unrestricted non-commercial use, distribution, and reproduction in any medium, provided the original work is properly cited. 


\section{Introduction}

An ideal neuromuscular blocking agent needs to take the shortest time in endotracheal intubation, the best intubating condition and have the shortest duration of muscle paralysis [1]. Particularly, the rapid sequence induction of anesthesia is indicated in emergency situations in the presence of full stomach or other conditions with an increased risk of aspiration.

In this point, rocuronium has the most rapid onset time among the currently available nondepolarizing neuromuscular blocking agents [2]. So rocuronium has become one of the most popular non-depolarizing neuromuscular blocking agents in clinical anesthesia.

Rocuronium is a neuromuscular blocking agent with intermediate action of duration, a bolus dose of $0.6 \mathrm{mg} / \mathrm{kg}$ produces a clinically acceptable intubating condition in 60-90 s in most children, adults and elderly patients [3]. However, because rocuronium was mostly metabolized in the liver and excreted through bile [4], the duration of neuromuscular blockade of rocuronium may be prolonged in patients with liver and kidney failure $[5,6]$.

Cisatracurium, the isomer of atracurium, is another kind of non-depolarizing neuromuscular blocking agent with intermediate action of duration. It is metabolized by Hoffmann elimination to laudanosine and a monoquaternary acrylate, like as atracurium [7]. Laudanosine has CNS stimulating properties. It is dependent on the liver and kidney for its elimination, and its concentration is elevated in patients with liver disease [8,9]. Cisatracurium is approximately three to four times as potent as atracurium. But cisatracurium produces laudanosine about five times less than atracurium does, and accumulation of this metabolite is not thought to be of any consequence in clinical practice [10]. In addition, cisatracurium does not release histamine in the range of clinical dose [11]. In spite of these advantages, the use of cisatracurium is limited because of slow onset and unsatisfactory intubating condition, compared with those seen with equipotent dose of other neuromuscular blocking agent [12-14].

Many studies have previously shown that endotracheal intubation may be accomplished without a neuromuscular blocking agent when anesthesia is induced with propofol and a short-acting opioid, such as remifentanil [15-19]. It is concluded that remifentanil and propofol might improve intubating condition, even if neuromuscular blocking agent is not used.

As such, we hypothesized that pretreatments of remifentanil and propofol before the administration of cisatracurium might provide an acceptable intubating condition comparable to that of rocuronium.

\section{Materials and Methods}

After obtaining approval from the Institutional Review Board and informed written consent from patients (52 American society of anesthesiologists 1 or 2 patients) aged 27-61, undergoing general anesthesia and endotracheal intubation for elective surgery, were enrolled in the study. Exclusion criteria were the history of drug or alcohol abuse, gastroesophageal reflux or hiatus hernia, cardiovascular disease, reactive airway disease, body mass index 30 or more, allergies to drugs frequently used in anesthesia, administration of sedative or narcotic drugs in previous $24 \mathrm{hr}$, renal or hepatic impairment, or higher than class II of Mallampati classification.

All patients were premedicated orally with $0.1 \mathrm{mg} / \mathrm{kg}$ of midazolam, 60 minutes before the induction of anesthesia. Before arriving at the operating room, patients had an IV catheter placed to allow administration of fluids and drugs. Patients were randomized using a random number generator to one of the two study groups to receive the following in a doubleblinded manner.

Standard monitoring, including noninvasive arterial pressure, ECG and pulse oximetry was applied and assessed continuously. Before induction of anesthesia, surface electrodes were placed over the ulnar nerve at the wrist.

After preoxygenation with $100 \%$ oxygen, anesthesia was induced with $2.0 \mathrm{mg} / \mathrm{kg}$ of intravenous propofol, given over 30 $\mathrm{s}$ immediately followed over $30 \mathrm{~s}$ of $0.5 \mu \mathrm{g} / \mathrm{kg}$ of remifentanil IV injection. After the loss of consciousness, the ulnar nerve was stimulated at the wrist with a square wave stimulus set at a current of $50 \mathrm{~mA}$ and duration of $0.2 \mathrm{~ms}$ [20]. Each stimulus was delivered in a train-of-four (TOF) sequence, and repeated every $12 \mathrm{~s}$ using a TOF Guards ${ }^{\circledR}$ (Organon Teknika $\mathrm{NV}$, Boxtel, Netherlands). The $\mathrm{R}$ group $(\mathrm{n}=23)$ received $0.9 \mathrm{mg} / \mathrm{kg}$ of rocuronium ( $3 \times \mathrm{ED}_{95}$ of rocuronium), and the $C$ group $(n=29)$ received $0.15 \mathrm{mg} / \mathrm{kg}$ of cisatracurium $\left(3 \times \mathrm{ED}_{95}\right.$ of cisatracurium), after the induction sequence. Rocuronium and cisatracurium syringes were prepared by an independent anesthesiologist in a total volume of $10 \mathrm{ml}$ with normal saline. We performed endotracheal intubation when the anesthesiologist thought it was 90 seconds after the drug administration and appropriate time for intubation. The anesthesiologist was skilled and was not involved in the anesthesia technique, and he was blinded to the neuromuscular blocking agent's type. The examiner, another anesthesiologist, recorded the time to intubation and suppression of maximal T1 on TOF. To avoid vocal cord injury, endotracheal intubation was not attempted if the vocal cords were fully closed. After intubation, anesthesia was maintained with $50 \%$ nitrous oxide in oxygen, and 2.0 vol\% sevoflurane (inspired). Intubating conditions were graded using the scoring scale initially 
Table 1. Intubating Condition

Intubating condition

\begin{tabular}{lll}
\hline 1 & Excellent & Easy passage of the tube without coughing. Vocal cords relaxed and abducted \\
2 & Good & Passage of the tube with slight coughing and/or bucking. Vocal cords relaxed and abducted \\
3 & Poor & Passage of tubes with moderate coughing and/or bucking. Vocal cords relaxed and abducted \\
4 & Not possible & Vocal cords not relaxed. Tightly adducted \\
\hline
\end{tabular}

Table 2. Demographic Characteristics of the Studied Patients

\begin{tabular}{lcc}
\hline & $\begin{array}{c}\text { R group } \\
(\mathrm{n}=23)\end{array}$ & $\begin{array}{c}\text { C group } \\
(\mathrm{n}=29)\end{array}$ \\
\hline Age (yr) & $45 \pm 10$ & $42 \pm 10$ \\
Sex (M/F) & $7 / 16$ & $9 / 20$ \\
Height $(\mathrm{cm})$ & $161 \pm 9$ & $162 \pm 9$ \\
Weight $(\mathrm{kg})$ & $59 \pm 9$ & $60 \pm 9$ \\
\hline
\end{tabular}

Values are Mean \pm SD. There were no statistically significant differences between the groups $(\mathrm{P}<0.05)$. The $\mathrm{R}$ group received rocuronium $(0.9$ $\mathrm{mg} / \mathrm{kg}$ ), and the C group received cisatracurium $(0.15 \mathrm{mg} / \mathrm{kg})$.

Table 3. The Estimated Intubation Time and Real Onset Time after Administration of Rocuronium or Cisatracurium

\begin{tabular}{lcc}
\hline & R group & C group \\
\hline Intubation time (s) & $118.0 \pm 34.6$ & $111.8 \pm 23.7$ \\
Onset time (s) & $102 \pm 49$ & $197 \pm 53^{*}$ \\
\hline
\end{tabular}

Values are Mean \pm SD. Intubation time: the time interval from the end of neuromuscular blocking agent administration to the endotracheal intubation. Onset time: the time interval from the end of neuromuscular blocking agent administration to the maximal suppression of $\mathrm{T} 1 \%$. * Statistically significant difference between groups ( $\mathrm{P}$ value $<0.05)$. $\mathrm{R}$ group rocuronium $(0.9 \mathrm{mg} / \mathrm{kg})$, $\mathrm{C}$ group received cisatracurium $(0.15 \mathrm{mg} / \mathrm{kg})$.

described by Goldberg et al. [21] (Table 1).

The onset time was defined as the time interval from the end of neuromuscular blocking agent administration to the maximal suppression of T1\%. Measurements of the heart rate (HR) and the mean arterial pressure (MAP) were made immediately before induction, immediately before tracheal intubation, and 1 min after tracheal intubation.

Statistical analysis was performed by using SPSS version 16.0 (SPSS Inc, Chicago, IL, USA). Quantitative data were expressed as the means $\pm \mathrm{SD}$, while qualitative data were expressed as numbers and percentages (\%). Student t-test was used on parametric data (age, weight, mean blood pressure, heart rate, onset time), paired within groups and unpaired between groups. The Mann-Whitney U-test was used for the interval data (intubating scores) and the Chi-squared test for nominal data (sex). Probability value $(\mathrm{P}$ value $)<0.05$ was considered statistically significant.

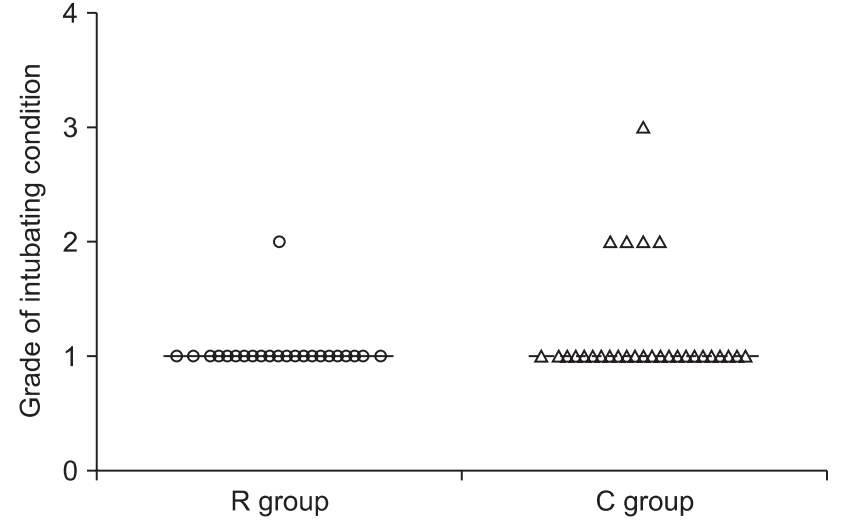

1. Excellent: Easy passage of the tube without coughing. Vocal cords relaxed and abducted.

2. Good: Passage of the tube with sligh coughing and/or bucking. Vocal cords relaxed and abducted.

3. Poor: Passage of tubes with moderate coughing and/or bucking. Vocal cords relaxed and abducted.

4. Not possible: Vocal cords relaxed, tightly abducted

Fig. 1. Intubating condition was described by distribution of patients each by grade of intubating condition. $R$ group rocuronium $(0.9 \mathrm{mg} /$ $\mathrm{kg})$, C group received cisatracurium $(0.15 \mathrm{mg} / \mathrm{kg})$.

\section{Results}

There were no significant differences in patient demographics between the two groups (Table 2). The endotracheal intubation was successful on the first attempt in all patients. The overall intubating conditions did not differ between the two groups $(\mathrm{P}=0.07)$. Intubating conditions were excellent in 22 patients in the R group and 24 patients in the $\mathrm{C}$ group (Fig. 1). Only one patient in the $\mathrm{C}$ group had poor intubating conditions. The remainder was rated as good. The various intubating scores are shown in Fig. 1, with no statistical significance between the two groups. The estimated time to intubation was similar in both groups $(118.0 \pm 34.6$ and $111.8 \pm 23.7$ seconds in the $\mathrm{R}$ and the $\mathrm{C}$ groups, respectively). But the real onset time was significantly longer in the $C$ group (197 \pm 53 s), compared with that of the R group $(102 \pm 49 \mathrm{~s})(\mathrm{P}<0.05$; Table 3$)$.

Hemodynamic changes within each group are summarized in Table 4. The baseline values for HR were similar in both groups (71 \pm 13 and $68 \pm 14 \mathrm{mmHg}$ in the $\mathrm{R}$ and the $\mathrm{C}$ groups, respectively). The HR recorded values of before intubation were 
Table 4. Heart Rate and Mean Arterial Blood Pressure Changes before and after Administration of Rocuronium or Cisatracurium

\begin{tabular}{lcccccccc}
\hline & \multicolumn{3}{c}{ Heart rate (beats/min) } & & \multicolumn{2}{c}{ Meanarterial blood pressure (mmHg) } \\
\cline { 2 - 3 } & Baseline & Before intubation & After intubation & & Baseline & Before intubation & After intubation \\
\hline R group & $71 \pm 13$ & $66 \pm 13^{*}$ & $85 \pm 17^{*, \dagger}$ & & $94 \pm 9$ & & $83 \pm 11^{*}$ & $103 \pm 23^{*,+}$ \\
C group & $68 \pm 14$ & $62 \pm 11^{*}$ & $77 \pm 16^{*, \dagger}$ & & $90 \pm 10$ & & $75 \pm 11^{*}$ & $95 \pm 16$ \\
\hline
\end{tabular}

Values are Mean $\pm \mathrm{SD}$. The R group received rocuronium $(0.9 \mathrm{mg} / \mathrm{kg})$, the C group received cisatracurium $(0.15 \mathrm{mg} / \mathrm{kg})$. There were $\mathrm{no}$ statistically significant differences between the $\mathrm{R}$ group and the $\mathrm{C}$ group. *Statistically significant difference versus Baseline reading ( $\mathrm{P}$ value $<$ $0.05) .{ }^{\dagger}$ Statistically significant difference versus Before intubation reading $(\mathrm{P}$ value $<0.05)$.

$66 \pm 12$ and $62 \pm 11 \mathrm{mmHg}$, respectively, with no statistically significant difference between the groups. After intubation of values for HR recorded were $85 \pm 17$ and $77 \pm 16 \mathrm{mmHg}$, respectively, with no statistically significant difference between the groups. And the HR decreased from the baseline in response to administration of induction agents in both groups, and increased from the baseline in response to intubation in both groups. The baseline values for MBP were similar in both groups (94 \pm 9 and $90 \pm 10 \mathrm{mmHg}$ in the $\mathrm{R}$ and the $\mathrm{C}$ groups, respectively). The MBP values before intubation were $83 \pm 11$ and $75 \pm 11 \mathrm{mmHg}$, respectively, with no statistically significant difference between the groups. The MBP values after intubation were $103 \pm 23$ and $95 \pm 16 \mathrm{mmHg}$, respectively, with no statistically significant difference between the groups. And the MBP decreased from the baseline in response to administration of induction agents in both groups, and increased from the baseline in response to intubation in the R groups, but showed no significant change in group $\mathrm{C}$.

\section{Discussion}

Cisatracurium has many advantages, compared with other neuromuscular blocking agent. Cisatracurium is a nondepolarising neuromuscular blocking agent with an intermediate duration of action. It is the cis isomer of atracurium besilate, and is approximately 3 to 4 -fold more potent than the mixture of isomers that constitute the parent drug. However, cisatracurium produces laudanosine about five times less than atracurium, and accumulation of this metabolite is not thought to be of any consequence in clinical practice. Relative to atracurium, cisatracurium has a lower propensity to cause histamine release, which is more potent but has a slightly longer onset time at equipotent doses [7]. And compared with vecuronium, cisatracurium besilate was associated with a significantly faster recovery after continuous infusion in patients in intensive care. It also offers a more predictable recovery profile than vecuronium after prolonged use in patients in intensive care $[8,9]$.

In our results, the onset time was determined as the time interval from the end of neuromuscular blocking agent administration to the maximal suppression of T1\%. In patients undergoing elective surgery, our report showed that the onset time of cisatracurium $(197 \pm 53 \mathrm{~s})$ was significantly longer compared to rocuronium (102 $\pm 49 \mathrm{~s})$. Nonetheless, we performed endotracheal intubation when the anesthesiologist thought it was 90 seconds after the drug administration and appropriate time for intubation. The estimated time to intubation was delayed, similar in both groups, from 90 seconds $(118.0 \pm 34.6$ and 111.8 \pm 23.7 seconds in the $\mathrm{R}$ and the $\mathrm{C}$ groups, respectively). We can get excellent or good tracheal intubating conditions in $96 \%$ of patients from a dose of cisatracurium $0.15 \mathrm{mg} / \mathrm{kg}$, which is similar to those achieved by $0.9 \mathrm{mg} / \mathrm{kg}$ of rocuronium (100\%), while supplementing a remifentanil and propofol combination.

We thought most of anesthesiologists can adjust the intubation time from the drug administration with the sense of mask ventilation. The estimated intubation time from our result seems to be a nonscientific or just an empirical method in anesthetic practice, but there is no case who cannot attempt if the vocal cords were fully closed. So, we can conclude the maximal suppression of T1 in TOF is not a good indicator for intubation from our results.

Although cisatracurium is more potent than the parent mixture (95\% effective dose $\left[\mathrm{ED}_{95}\right] 0.05 \mathrm{mg} / \mathrm{kg}$ vs. $\left.0.2 \mathrm{mg} / \mathrm{kg}\right)$, its pharmacodynamic profile is similar to that of atracurium, except for a reportedly slower onset [6]. Bluestein et al. [22] reported that increasing the initial dose of cisatracurium (from 0.1 to 0.15 and $0.2 \mathrm{mg} / \mathrm{kg}$ ), decreased the mean time of onset (from 4.6 to 3.4 and $2.8 \mathrm{~min}$, respectively) and increased the mean time of clinically effective duration (45 to 55 and $61 \mathrm{~min}$, respectively). Mellinghoff et al. [12] estimated that the onset time was $3.1 \pm$ 1.0 min with cisatracurium. Mandal [23] conducted a study to find out about the minimum possible dose of cisatracurium for achieving excellent to good intubating conditions within $90 \mathrm{~s}$ of its administration under general anesthesia. After induction of anesthesia with the standardized method, group I $(n=20)$ received $0.15 \mathrm{mg} / \mathrm{kg}$, group $\mathrm{II}(\mathrm{n}=20)$ received $0.2 \mathrm{mg} / \mathrm{kg}$ and group III $(\mathrm{n}=20)$ received $0.25 \mathrm{mg} / \mathrm{kg}$ of cisatracurium. They concluded that the minimum dose required to achieve excellent to good intubating conditions with cisatracurium is $0.20 \mathrm{mg} /$ $\mathrm{kg}$ at $90 \mathrm{~s}$ after its administration. Doses of $0.15 \mathrm{mg} / \mathrm{kg}(3 \times$ 
$\left.\mathrm{ED}_{95}\right)$ and $0.2 \mathrm{mg} / \mathrm{kg}\left(4 \times \mathrm{ED}_{95}\right)$ of cisatracurium, as components of a propofol/nitrous oxide/oxygen induction intubation technique, may produce generally good or excellent conditions of intubation in 2.0 and $1.5 \mathrm{~min}$, respectively [24]. In accordance with these results, we can conclude that at the same dose $(3 \times$ $\mathrm{ED}_{95}$ ) atracurium would not create a superior onset time and intubating condition, compared with rocuronium after $90 \mathrm{~s}$.

On the other hand, recent studies have suggested that propofol in combination with short-acting opioid, such as alfentanil or remifentanil, may provide adequate conditions for laryngoscopy and endotracheal intubation, without using neuromuscular blocking agents for several properties of these drugs.

First of all, remifentanil has a property of analgesic efficacy and respiratory depressant effect. The opioid remifentanil is a potent fentanyl derivative. Remifentanil has unique properties and undergoes rapid hydrolysis. It has a rapid termination of actions due to hydrolysis by non-specific tissue esterases with a context sensitive half-life of just over $3 \mathrm{~min}$, allowing rapid return of spontaneous respiration. Although the onset of effect is similar to that of alfentanil, within one to two minutes, it has a shorter half-life and the time to recovery is not greatly influenced by the dose [22]. Those clinical properties make remifentanil the short-acting opioid of choice for circumstances, in which an intense opioid effect of short duration is required. Based on its analgesic efficacy and its respiratory depressant effect, remifentanil is 20 to 30 times more potent than alfentanil, after a single bolus dose [22]. In a recent study, Stevens and Wheatley [18] showed that when used in combination of $2 \mathrm{mg} /$ $\mathrm{kg}$ of propofol, $3-4 \mu \mathrm{g} / \mathrm{kg}$ of remifentanil provides satisfactory intubating conditions, more reliably than $1-2 \mu \mathrm{g} / \mathrm{kg}$ of remifentanil. But a high dose of opioid would cause a prolonged apnea and a fatal decrease in arterial blood pressure, during induction of anesthesia. So in our study, the low dose was chosen in an attempt to minimize the effects on apnea time and cardiovascular parameters.

In the second place, propofol has a property of depressant effect on pharyngeal and laryngeal muscles. The vocal cord sequelae occur more frequently in patients for whom tracheal intubation is attempted in a situation of unacceptable neuromuscular blocking. Supplementing a propofol-opioid induction regimen with a non-depolarizing neuromuscular blocking agent improves the quality of endotracheal intubation and decreases postoperative hoarseness [24]. McKeating et al. [25] investigated the depressant effects of induction doses of thiopentone and propofol on airway integrity and reactivity. They found that, when no neuromuscular blocking agents were given, laryngoscopy was easier to perform after propofol than after an equipotent dose of thiopentone, and that pharyngeal and laryngeal activity were more depressed after administration of propofol than after of thiopentone. Using a fiberoptic laryngoscope, Barker et al. [26] assessed the vocal cord movement after induction of anesthesia with either propofol or thiopentone, and observed that vocal cords adducted to a greater extent after induction of anesthesia with thiopentone than with propofol. More recently, Eames et al. [27] compared the effects of etomidate, propofol and thiopentone on respiratory resistance after tracheal intubation. Anesthesia was induced with either $2.5 \mathrm{mg} / \mathrm{kg}$ of propofol, 5 $\mathrm{mg} / \mathrm{kg}$ of thiopentone or $0.4 \mathrm{mg} / \mathrm{kg}$ of etomidate. Respiratory resistance after tracheal intubation was lower after induction with propofol than after induction with thiopental or with highdose etomidate. In accordance with these results, we found that pharyngeal and laryngeal activities were more depressed after the administration of propofol than after thiopentone or etomidate, although, we used a relatively low dose of propofol.

These findings should be considered within the context of the limitation of this study. First, the non-treated control group, without remifentanil, was not included in this study. However, because we performed endotracheal intubation when the anesthesiologist thought it was 90 seconds after the drug administration and appropriate time for intubation at earlier point compared with usual onset time of cisatracurium, including a non-treated arm would not have been ethical. Second, we did not use the higher doses of remifentanil. Higher doses of remifentanil would possibly produce further improvement in intubating condition. This will be of clinical benefit if it is not associated with an increase in the incidence of complications.

In conclusion, our report shows that the onset time of cisatracurium was significantly longer, compared to rocuronium. However, a small dose of $0.15 \mathrm{mg} / \mathrm{kg}$ of cisatracurium, supplementing a remifentanil-propofol combination, provides excellent or good endotracheal intubating conditions in $96 \%$ of patients, a rate similar to those achieved by rocuronium $0.9 \mathrm{mg} / \mathrm{kg}$ (100\%), while using the same anesthetic technique and similar induction time. With such technique, we were able to reproduce the advantages of cisatracurium, such as non-accumulation of metabolite. This technique could be applied in patients with liver and kidney failures for brief surgical procedures to obtain short time to intubation and excellent intubating conditions.

\section{References}

1. Sluga M, Ummenhofer W, Studer W, Siegemund M, Marsch SC. Rocuronium versus succinylcholine for rapid sequence induction of anesthesia and endotracheal intubation: a prospective, randomized trial in emergent cases. Anesth Analg 2005; 101: 1356-61.

2. Perry J, Lee J, Wells G. Rocuronium versus succinylcholine for rapid sequence induction intubation. Cochrane Database Syst Rev 2003; 1: CD002788. 
3. Sparr HJ, Beaufort TM, Fuchs-Buder T. Newer neuromuscular blocking agents: how do they compare with established agents? Drugs 2001; 61: 919-42.

4. Khuenl-Brady K, Castagnoli KP, Canfell PC, Caldwell JE, Agoston $\mathrm{S}$, Miller RD. The neuromuscular blocking effects and pharmacokinetics of ORG 9426 and ORG 9616 in the cat. Anesthesiology 1990; 72: 669-74.

5. van Miert MM, Eastwood NB, Boyd AH, Parker CJ, Hunter JM. The pharmacokinetics and pharmacodynamics of rocuronium in patients with hepatic cirrhosis. Br J Clin Pharmacol 1997; 44: 13944.

6. Robertson EN, Driessen JJ, Booij LH. Pharmacokinetics and pharmacodynamics of rocuronium in patients with and without renal failure. Eur J Anaesthesiol 2005; 22: 4-10.

7. Wastila WB, Maehr RB, Turner GL, Hil DA, Savarese JJ. Comparative pharmacology of cisatracurium (51W89), atracurium, and five isomers in cats. Anesthesiology 1996; 85: 169-77.

8. Canfell PC, Castagnoli N Jr, Fahey MR, Hennis PJ, Miller RD. The metabolic disposition of laudanosine in dog, rabbit, and man. Drug Metab Dispos 1986; 14: 703-8.

9. Parker CJ, Hunter JM. Pharmacokinetics of atracurium and laudanosine in patients with hepatic cirrhosis. Br J Anaesth 1989; 62: 177-83

10. Kisor DF, Schmith VD, Wargin WA, Lien CA, Ornstein E, Cook DR. Importance of the organ-independent elimination of cisatracurium. Anesth Analg 1996; 83: 1065-71.

11. Lien CA. The role of steroisomerism in neuromuscular blocking drugs. Curr Opin Anesthesiol 1996; 9: 348-53.

12. Mellinghoff $\mathrm{H}$, Radbruch L, Diefenbach C, Buzello W. A comparison of cisatracurium and atracurium: onset of neuromuscular block after bolus injection and recovery after subsequent infusion. Anesth Analg 1996; 83: 1072-5.

13. Kirov K, Motamed C, Decailliot F, Behforouz N, Duvaldestin P. Comparison of the neuromuscular blocking effect of cisatracurium and atracurium on the larynx and the adductor pollicis. Acta Anaesthesiol Scand 2004; 48: 577-81.

14. Correa CM, Sudo GZ, Sudo RT. Hemodynamic effects of atracurium and cisatracurium and the use of diphenhydramine and cimetidine. Rev Bras Anestesiol 2010; 60: 52-63.

15. Schlaich N, Mertzlufft F, Soltesz S, Fuchs-Buder T. Remifentanil and propofol without muscle relaxants or with different doses of rocuronium for tracheal intubation in outpatient anaesthesia. Acta Anaesthesiol Scand 2000; 44: 720-6.

16. Barclay K, Eggers K, Asai T. Low-dose rocuronium improves conditions for tracheal intubation after induction of anaesthesia with propofol and alfentanil. Br J Anaesth 1997; 78: 92-4.

17. Taha S, Siddik-Sayyid S, Alameddine M, Wakim C, Dahabra C, Moussa A, et al. Propofol is superior to thiopental for intubation without muscle relaxants. Can J Anaesth 2005; 52: 249-53.

18. Stevens JB, Wheatley L. Tracheal intubation in ambulatory surgery patients: using remifentanil and propofol without muscle relaxants. Anesth Analg 1998; 86: 45-9.

19. Klemola UM, Mennander S, Saarnivaara L. Tracheal intubation without the use of muscle relaxants: remifentanil or alfentanil in combination with propofol. Acta Anaesthesiol Scand 2000; 44: 4659 .

20. Plaud B, Debaene B, Donati F. The corrugator supercilii, not the orbicularis oculi, reflects rocuronium neuromuscular blockade at the laryngeal adductor muscles. Anesthesiology 2001; 95: 96-101.

21. Goldberg ME, Larijani GE, Azad SS, Sosis M, Seltzer JL, Ascher J, et al. Comparison of tracheal intubating conditions and neuromuscular blocking profiles after intubating doses of mivacurium chloride or succinylcholine in surgical outpatients. Anesth Analg 1989; 69: 93-9.

22. Bluestein LS, Stinson LW Jr, Lennon RL, Quessy SN, Wilson RM. Evaluation of cisatracurium, a new neuromuscular blocking agent, for tracheal intubation. Can J Anaesth 1996; 43: 925-31.

23. Mandal P. Intubating conditions after cisatracurium administration - a dose response study in adults. J Anaesth Clin Pharmacol 2002; 18: 147-51.

24. Schmautz E, Deriaz H, Vrillon M. Evaluation of 51W89 for endotracheal intubation in surgical patients during N2O/O2/propofol anesthesia. Anesthesiology 1994; 81: 1081.

25. McKeating K, Bali IM, Dundee JW. The effects of thiopentone and propofol on upper airway integrity. Anaesthesia 1988; 43: 638-40.

26. Barker P, Langton JA, Wilson IG, Smith G. Movements of the vocal cords on induction of anaesthesia with thiopentone or propofol. $\mathrm{Br}$ J Anaesth 1992; 69: 23-5.

27. Eames WO, Rooke GA, Wu RS, Bishop MJ. Comparison of the effects of etomidate, propofol, and thiopental on respiratory resistance after tracheal intubation. Anesthesiology 1996; 84: 1307-11. 